\title{
Diagnostic Accuracy of Magnetic Resonance Arthrography in Detecting Intra-articular Pathology Associated with Femoroacetabular Impingement
}

\author{
Christian Carulli ${ }^{1}$ Filippo Tonelli ${ }^{1}$ Tommaso Melani ${ }^{1}$ Michele Pietragalla ${ }^{2}$ \\ Alioscia Giancarlo Domenico De Renzis ${ }^{2}$ Giuseppe Caracchini ${ }^{2}$ Massimo Innocenti ${ }^{1}$ \\ 1 Orthopaedic Clinic, Orthopaedic Traumatologic Center, Azienda \\ Ospedaliero-Universitaria Careggi, Florence, Italy \\ 2 Radiology Unit, Orthopaedic Traumatologic Center, Azienda \\ Ospedaliero-Universitaria Careggi, Florence, Italy \\ Address for correspondence Christian Carulli, MD, Orthopaedic \\ Clinic, Orthopaedic Traumatologic Center, Azienda Ospedaliero- \\ Universitaria Careggi, Florence 50139, Italy \\ (e-mail: christian.carulli@unifi.it).
}

Joints 2018;6:104-109.

\begin{abstract}
Keywords

- femoroacetabular impingement

- CAM

- pincer

- magnetic resonance arthrography

- diagnostic accuracy
\end{abstract}

Purpose The aim of this study was to assess the diagnostic accuracy of magnetic resonance arthrography (MRA) in the detection of intra-articular lesions of the hip in patients affected by femoroacetabular impingement (FAI) by using arthroscopy as reference standard.

Methods Twenty-nine consecutive hip arthroscopies performed in 24 patients were considered for the study. Patients had a mean age of 38.3 years. Ultrasound-guided 1.5T MRA was performed with precontrast short tau inversion recovery, T1-weighted and PD coronal, T1-weighted, and T2-weighted axial with 3-mm-thick slice sequences, and postcontrast T1-weighted fat saturation MRA (Fat-SAT) axial, coronal and oblique sagittal, and T1-weighted Vibe 3D coronal sequences with MPR sagittal, axial, and radial reconstructions with 2-mm-thick slice and coronal density protonil (DP) Fat-SAT. Sensitivity, specificity, positive predictive value (PPV), and negative predictive value (NPV) of MRA were evaluated by comparison arthroscopy for the following intraarticular findings: acetabular and femoral chondral lesions, labral degeneration, labral tears, synovitis, ligamentum teres (LT) tears, CAM lesions, pincer lesions, loose bodies, and osteophytes.

Results An absolute per cent agreement (100\%) was observed for all the variables in the assessment of CAM lesions. Sensitivity, specificity, PPV, and NPV of MRA were 100, $68.4,72.7$, and $100 \%$, respectively, for acetabular chondral lesions; $100,50,47.3$, and $100 \%$, respectively, for femoral chondral lesions; $33,85,20$, and $91.6 \%$, respectively, for labral tears; 95, 71, 91.3, and 83.3\%, respectively, for labral degeneration; 100, 88, 57.1 , and $100 \%$, respectively, for LT tears; $33.3,85,50$, and $73.9 \%$, respectively, for pincer lesions; $50,96,66.6$, and $92.3 \%$, respectively, for intra-articular loose bodies; and $100,73.9,50$, and $100 \%$, respectively, for osteophytes.

Conclusion MRA may play an important role in detecting intra-articular lesions associated with FAl. This might be helpful for the preoperative planning before hip arthroscopy.

Level of Evidence This is a Level 2, diagnostic accuracy study compared with gold standard. received

August 31, 2017

accepted

May 13, 2018

published online

June 20, 2018
Copyright $\odot 2018$ Georg Thieme Verlag License terms

KG Stuttgart · New York
(ब) $\Theta \circledast$ 


\section{Introduction}

Femoroacetabular impingement (FAI) is today considered one of the main cause of symptomatic early hip arthritis in young patients. ${ }^{1} \mathrm{FAI}$ is induced by an incongruence between the femoral head and the acetabulum due to an alteration of the head-neck junction ("CAM"), of the acetabular rim ("pincer"), or a mix of both conditions. ${ }^{2,3}$ Symptoms are represented by groin pain, irradiated usually to the thigh and buttock, and often associated to clicks during hip rotations. Range of motion is usually limited by the early contact between these bone alterations and forced passive motion activities are symptomatic.

Some clinical tests (Flexion-Adduction-Internal Rotation (FADDIR), Flexion, ABduction, and External Rotation (FABER) Ribas, and posterior impingement) are useful to have a suspect, but the confirmation with imaging studies is crucial. ${ }^{1,4,5}$ Conventional radiology is essential for the diagnosis of FAI by the use of various specific projections. "True" anterior-posterior, Dunn at 45 and 90 degrees, frog leg, and Lequesne "false profile" are some of the most used radiologic views. ${ }^{6,7}$ Common findings evaluable by radiology are the "pistol grip" deformity, the crossover sign, the overcoverage of the acetabular rim ("eight sign"), and the alterations of the $\alpha$ and the center-edge angles. ${ }^{8,9}$ Such findings are usually sufficient to plan surgical treatment of the various deformity. However, alterations of intra-articular structures are not detected by standard radiology and may need further treatment during surgery.

Hip arthroscopy is considered the gold standard of treatment for FAI; it is associated with good outcomes and with lesser morbidity with respect to open surgical dislocation, originally described as the most indicated procedure. ${ }^{10,11}$

Magnetic resonance imaging (MRI) and computed tomography (CT) are useful to add information about other intraarticular lesions and to better visualize the profile of bones, respectively. ${ }^{7,12,13}$ Direct 3-T MRI may be useful alone in the detection of soft tissue alterations, but it is not diffusely available. ${ }^{14}$ The use of MR with intra-articular injection of gadolinium contrast (MR arthrography [MRA]) is a valid diagnostic tool to evaluate cartilage, synovial membrane, labrum, and ligamentum teres (LT). However, diagnostic accuracy of this exam is still under debate. ${ }^{15-17}$

The aim of this study was to assess the diagnostic accuracy of MRA in the detection of intra-articular lesions of the hip in patients affected by FAI by using arthroscopy as reference standard. The hypothesis of the study was that MRA is a valid diagnostic exam to detect intra-articular lesions in hips affected by FAI.

\section{Methods}

Twenty-nine consecutive hip arthroscopies performed between June 2012 and April 2016 in 24 patients affected by symptomatic FAI (five patients underwent a bilateral-staged procedure) were considered for this study. The Institutional Review Board approved the study and all patients were adequately informed about the diagnostic procedure, treat- ment, and follow-up. Inclusion criteria were symptomatic FAI with persistent pain and functional limitation without any other source of groin or irradiated pain. Exclusion criteria were patients with advanced hip osteoarthritis (OA), and other sources of groin or irradiated pain (discal hernia, inguinal disruption, muscular tears). Eighteen patients were males and 6 females. The mean age was 38.3 years (range, $18-59$ years), the mean body mass index was 20.4 (range, 20-22).

Each patient underwent a specific diagnostic protocol. The medical history was focused on the acquisition of the gait ability during childhood, the results of the early ultrasound screening performed few months after birth, and the presence of clicks in the hip. The radiologic study consisted in the true anteroposterior standing, the bilateral false profile, and the 45- and 90-degree Dunn views of both hips. ${ }^{18,19}$

All patients underwent an MRA with a 1.5-T machine (Siemens Medical Solution, MR Area, Erlangen, Germany). No patients referred allergy or contraindications to arthrography. All procedures were performed by the same radiologist (G.C.) and consisted of local disinfection and anesthesia with $1 \%$ lidocaine followed by the intra-articular injection of diluted gadolinium through an anterior ultrasound-guided portal using a probe cover and sterile gel. The following sequences of the preliminary direct MRI were obtained: short tau inversion recovery, T1-weighted and PD coronal, T1-weighted, and T2-weighted axial with 3-mm-thick slices. After contrast injection, further sequences were obtained: T1-weighted fat saturation MRA (Fat-SAT) axial, coronal and oblique sagittal, T1-weighted Vibe 3D coronal sequences with MPR sagittal, axial and radial reconstructions with 2mm-thick slice, and coronal density protonil (DP) Fat-SAT. The purpose of such sequences was to evaluate any tissue in the joint (cartilage, labrum, capsula, synovial membrane and its folds, LT, and bones). Any pincer lesion was evaluated on precontrast axial oblique PD-weighted MR sequences.

All arthroscopies were performed by the same surgeon (C.C.) with patients on lateral position on a standard surgical bed with a dedicated hip traction system and by the use of an imaging intensifier. The first surgical step consisted of the evaluation of the central compartment under traction. After traction release, the second step consisted of peripheral compartment evaluation.

Radiological and arthroscopic evaluation were performed independently and blinded each other. Acetabular and femoral chondral lesions were classified according to the Outerbridge classification ${ }^{20}$ and staged as low grade (grades $0-2$ ) and high grade (grades 3 and 4). Other intra-articular findings were labral degeneration, labral tears, synovitis, LT tears, CAM lesions, pincer lesions, loose bodies, and osteophytes. All these findings were handled as dichotomous variables and staged as "yes or no."

All patients' data were recorded in a custom-made database. The statistical analysis was performed using SPSS software v. 11.0 (SPPS Inc, Chicago, Illinois, United States). Absolute per cent agreement, sensitivity, specificity, positive predictive value (PPV), and negative predictive value (NPV) of MRA were calculated by the $2 \times 2$ table method and by assuming the arthroscopic assessment as reference standard. 

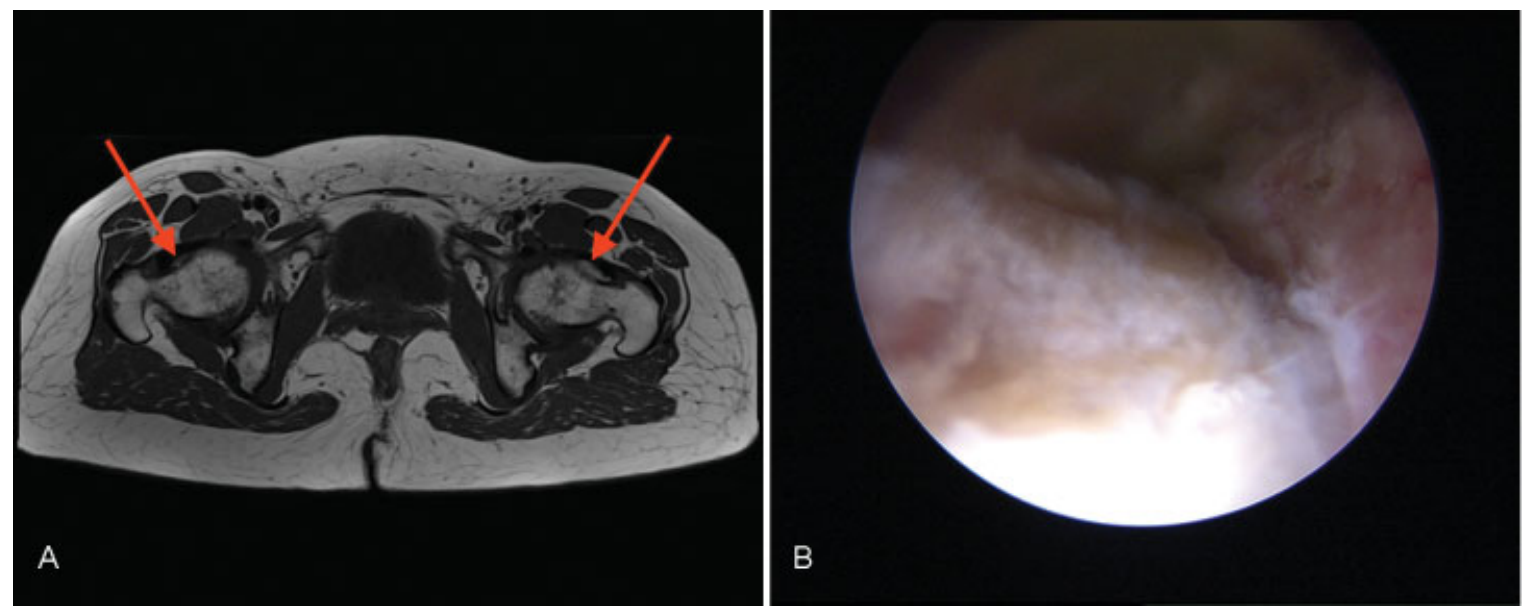

Fig. 1 T1 TSE axial, TR: 500, pelvis; TE: 22 milliseconds. (A) Bilateral bumps (red arrows) in a patient with bilateral CAM-type FAI with capsular thickening, more prominent on the left side. (B) Intraoperative aspect of the same large bump of the left femoral head before distraction.

\section{Results}

Absolute per cent agreement between MRA and arthroscopy was observed in $79.3 \%$ of the cases for acetabular chondral lesions, $65.5 \%$ for femoral chondral lesions, $89.6 \%$ for labral degeneration, $79.3 \%$ for labral tears, $75.8 \%$ for synovitis, $89.6 \%$ for LT tears, $89.6 \%$ for loose bodies, and $82.7 \%$ for osteophytes. A full agreement (100\%) was observed for CAM lesions, whereas agreement for pincer lesions correspondence was $68.9 \%$ (-Figs. 1-4).

Sensitivity was high for all the variables investigated, except for labral tears, pincer lesions, and loose bodies. Specificity was high for labral tears, LT tears, CAM lesions, pincer lesions, and loose bodies, while it was moderate for all the other variables. PPV was high only for labral degeneration and CAM lesions, whereas it was moderate to poor for all the other variables. NPV was high for all the variables, except pincer lesions ( - Table $\mathbf{1}$ ).

\section{Discussion}

FAI is more frequent than believed until years ago, and it represents a common source of groin pain, ${ }^{21}$ which is often (but not exclusively) related to bone alterations of acetabulum and proximal femur. While bone alterations are easy to detect, soft tissue evaluation is not simple. Standard radiology is dramatically important, but CT and MRI may also be useful. Specifically, MRI usually provides more information on the status of soft tissues than $\mathrm{CT}^{13}$ without irradiation of the patients. As for other joints, the use of an intra-articular contrast medium improves the diagnostic accuracy of MR. ${ }^{14,15}$ At MRA, CAM impingement appears on coronal and axial images as a lacking offset between femoral head and neck, with a focal osseous bump at their junction. FAI is often associated to fibrocystic changes at the femoral head-neck junction that can be early detected on MRA as small cysts of varying diameter. ${ }^{22,23}$ Pincer impingement may be related to focal or global acetabular over-coverage. On MRA, the pincer morphology can be evaluated on axial images drawing a line between the lateral edges of the acetabulum. This method allows a better accuracy in the assessment of acetabular alterations with respect to the crossover sign on standard X-rays; the latter evaluation may often overrate an acetabular retroversion due to the tilt and the inclination of the pelvis on the X-ray tube. ${ }^{14}$

Labral degeneration, labral lesions, and chondral lesions are generally well detected on MRA. ${ }^{24-28}$ In a meta-analysis
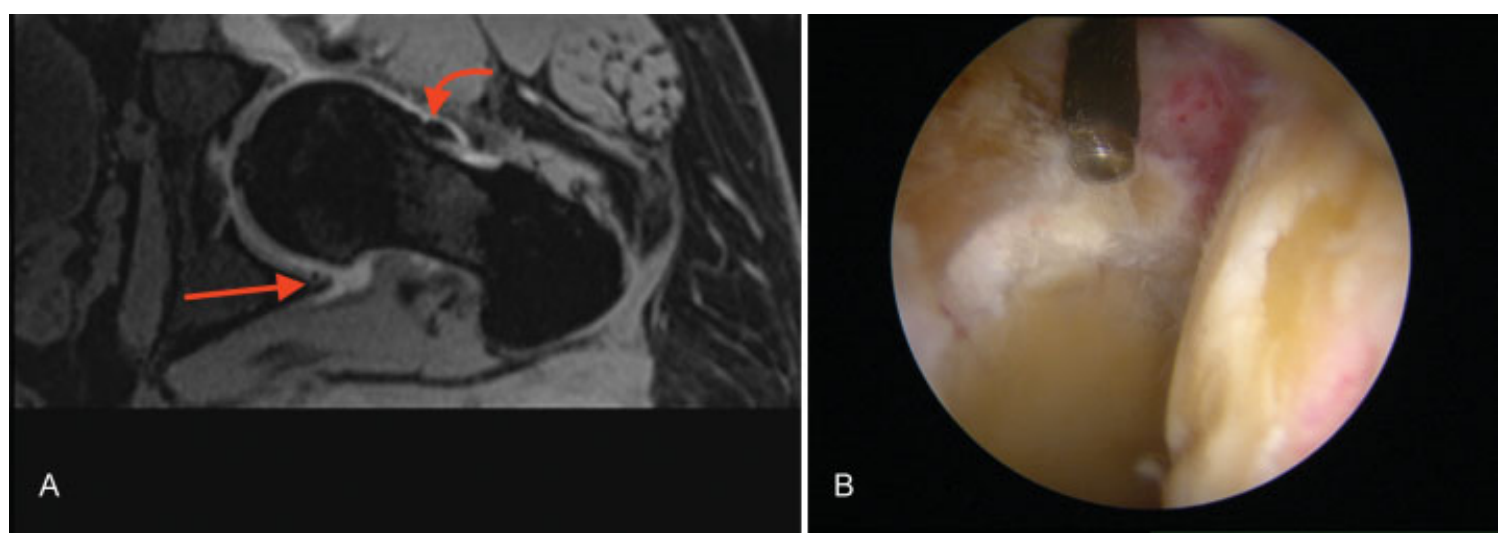

Fig. 2 MPR mdc VIBE axial, left hip; TR: 19, TE: 5.93 milliseconds. (A) Fissuring and fragmentation of the labrum at the inferior-medial position (straight red arrow) and a bump on the femoral head/neck junction (curved red arrow) in a patient with CAM-type FAI. (B) Intraoperative finding, demonstrating the alterations as observed at MRA. 

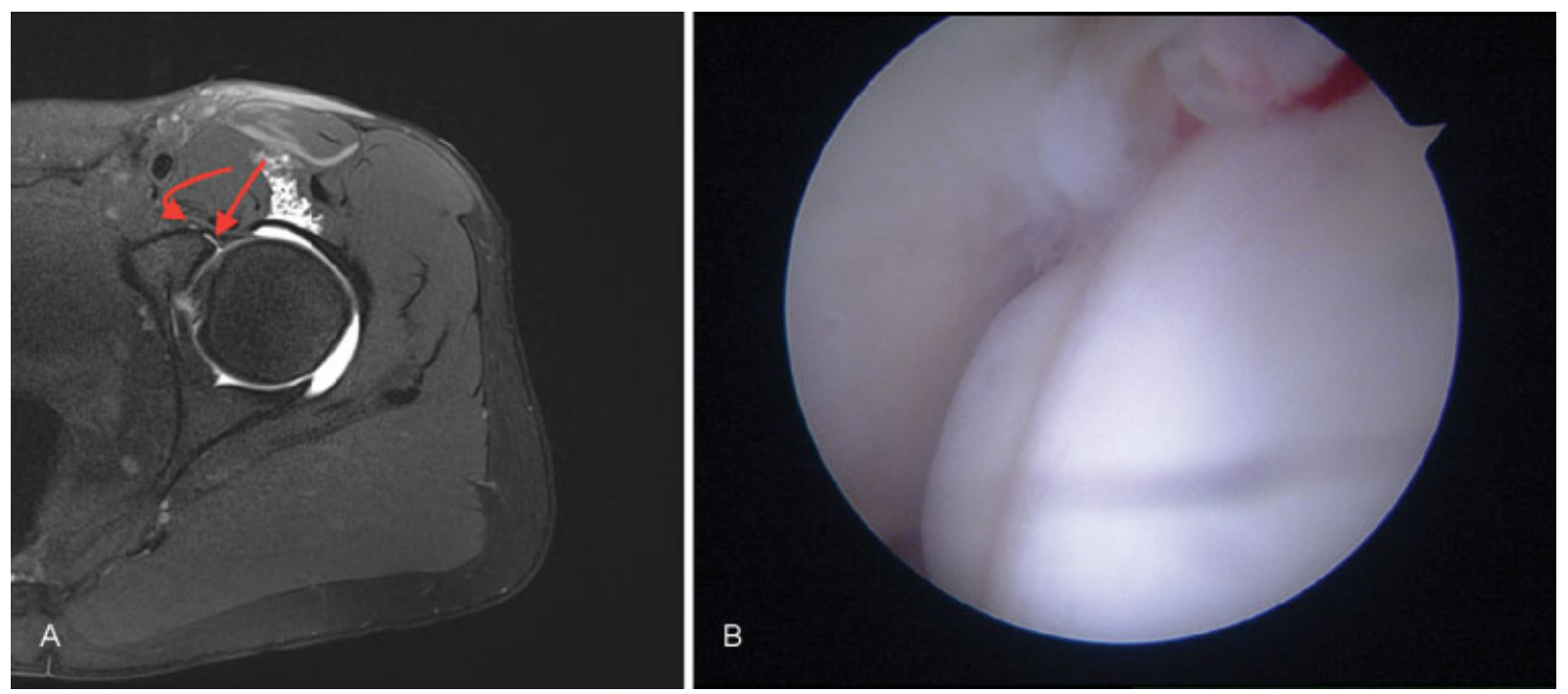

Fig. 3 T1 TSE mdc FS, left hip; TR: 525, TE: 29 milliseconds. Fissuring of the superior-external labrum (straight red arrow) with very small extracapsular leak of contrast agent (curved red arrow) and intact periosteum in patient with CAM-type FAI. (A) These features are very suggestive of a labral tear. (B) Arthroscopy exactly confirmed the finding.
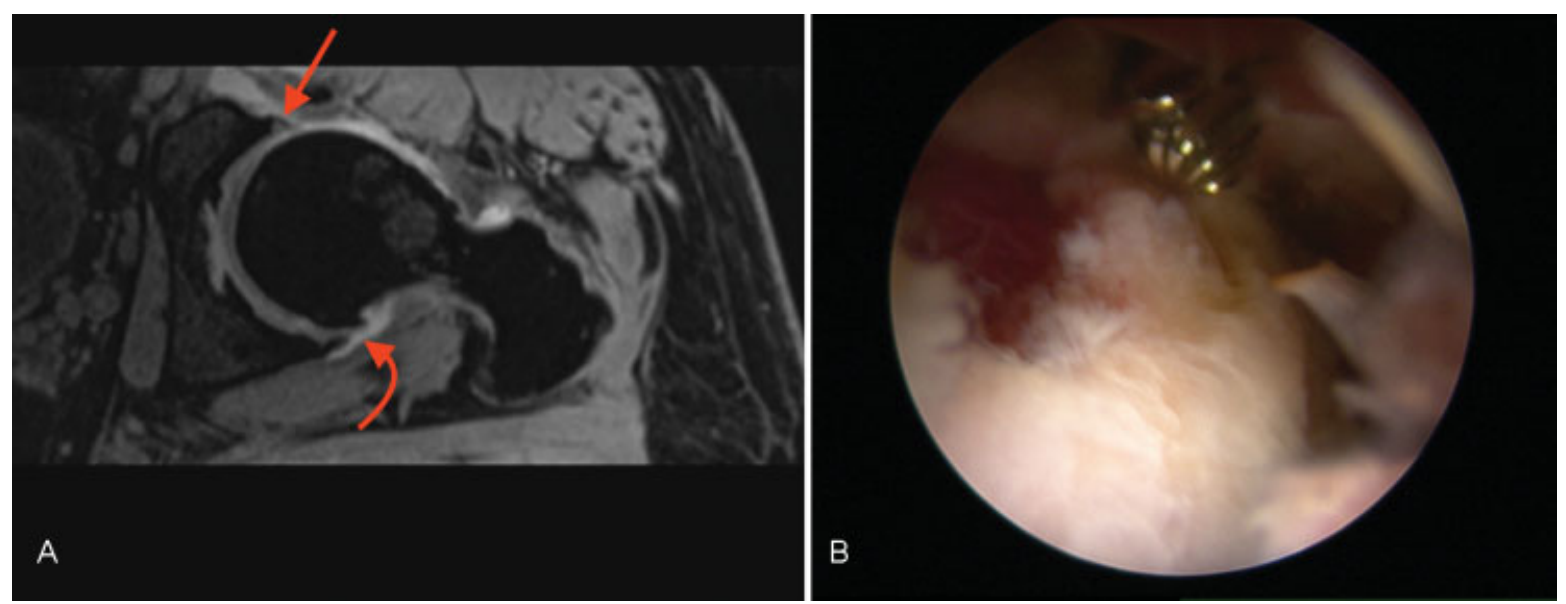

Fig. 4 MPR mdc VIBE axial, left hip; TR: 19, TE: 5.93 milliseconds. Signal intensity alteration of the superior-external labrum without fissuring and/or detachment (straight red arrow). (A) Early sign of osteoarthritis of the hip with osteophytes in the inferior-medial position (curved red arrow). (B) During arthroscopy, there was a full correspondence of the lesion and its position.

Table 1 Sensitivity, specificity, PPV, and NPV are shown for all the tested pathologic findings

\begin{tabular}{|l|l|l|l|l|l|l|l|l|l|}
\hline & $\begin{array}{l}\text { Chondral } \\
\text { lesions } \\
(\mathrm{A})\end{array}$ & $\begin{array}{l}\text { Chondral } \\
\text { lesions } \\
(\mathrm{FH})\end{array}$ & $\begin{array}{l}\text { Labral } \\
\text { tears }\end{array}$ & $\begin{array}{l}\text { Labral } \\
\text { degeneration }\end{array}$ & $\begin{array}{l}\text { LT } \\
\text { tears }\end{array}$ & $\begin{array}{l}\text { CAM } \\
\text { lesions }\end{array}$ & $\begin{array}{l}\text { Pincer } \\
\text { lesions }\end{array}$ & $\begin{array}{l}\text { Loose } \\
\text { bodies }\end{array}$ & OP \\
\hline $\begin{array}{l}\text { Sensitivity } \\
(\%)\end{array}$ & 100 & 100 & 33 & 95 & 100 & 100 & 33 & 50 & 100 \\
\hline $\begin{array}{l}\text { Specificity } \\
(\%)\end{array}$ & 68.4 & 50 & 85 & 71 & 88 & 100 & 85 & 96 & 73.9 \\
\hline PPV (\%) & 72.7 & 47.3 & 20 & 91.3 & 57.1 & 100 & 50 & 66.6 & 50 \\
\hline NPV (\%) & 100 & 100 & 91.6 & 83.3 & 100 & 100 & 73.9 & 92.3 & 100 \\
\hline
\end{tabular}

Abbreviations: A, acetabulum; FH, femoral head; LT, ligamentum teres; OP, osteophytes; PPV, positive predictive value; NPV, negative predictive value. 
conducted by Smith et al, ${ }^{24} 16$ studies on MRA of the hip were evaluated demonstrating sensitivity of $87 \%$ and specificity of $64 \%$ in the detection of labral tears. Such value of specificity was quite similar to that reported in this study, confirming its good capacity in excluding labral tears. However, poor PPV in our study is probably related to the presence of anatomical variants of the labrum that frequently occurs very close to the lesions, particularly in the anterior-superior zone of the acetabulum. ${ }^{25}$ Poor sensitivity observed was mainly due to limited number of labral lesions found during arthroscopy.

There is not a univocal interpretation regarding the detection of chondral lesions. Ho et $\mathrm{al}^{26}$ considered MRA useful to detect high-grade chondral lesions, while Mintz et al also reported a good evaluation of grade-2 lesions. ${ }^{27}$ In other studies, the exact grade of chondral damage has not clearly specified, thus making data interpretation rather difficult. ${ }^{28,29}$

In our study, MRA showed sensitivity and NPV of $100 \%$ in the evaluation of both acetabular and femoral chondral lesions; therefore, the presence of low-grade chondral lesions at MRA is an optimal predictor of the absence of high-grade chondral lesions during arthroscopy. Conversely, MRA showed suboptimal specificity and PPV in the evaluation of high-grade acetabular lesions and poor specificity and PPV in the evaluation of femoral lesions. Indeed, in our study, preoperative MRA often overestimated chondral lesions observed successively during arthroscopy, particularly on the femoral side. The incidence and the severity of acetabular lesions was higher than femoral ones, as Li et al previously observed. ${ }^{14}$ Overall, the results of this study for chondral lesions are similar to the recent literature regarding this topic. ${ }^{14}$ Therefore, MRA may have an important role in excluding advanced acetabular and femoral lesions. ${ }^{30}$

MRA may be useful in the evaluation of LT tears. The low specificity and PPV could be due to the presence of intraligament degeneration and lesions that cannot be visualized during arthroscopy. Moreover, DP sequences have been introduced in the MRA study after the first three procedures, to improve its visualization. However, LT tears were identified in $13.8 \%$ of cases; this prevalence was similar to those reported in other studies, ranging from 4 to $51 \% .^{31-34}$

Suboptimal specificity of MRA in the assessment of acetabular and femoral osteophytes was probably due to poor visualization of the inferior-medial region of the hip joint during arthroscopy.

In our study, MRA depicted very well CAM lesions, whereas it showed suboptimal specificity and NPV, and poor sensitivity and PPV in the assessment of pincer lesions.

The overall rationale of MRA of the hip in FAI would be to allow a better planning of arthroscopic procedures. If X-rays and CT may be sufficient to plan the osteoplasty of bone alterations, MRA may indicate where it would be necessary for labral repair or debridement, when to perform microfractures for chondral lesions, or finally when is indicated debridement of LT. MRA showed a good correlation with preoperative X-ray findings. However, in patients with no radiologic signs of OA, MRA often revealed high-grade acetabular and femoral chondral lesions. A correlation between
MRA and X-rays for pincer lesion was difficult due to the different method of evaluation ("eight sign" on standing position vs. acetabular over-coverage on supine position). In our study, X-ray evaluation showed a superior correlation with arthroscopy than with MRA.

This study has some limitations. First, it represents a preliminary study. The number of patients is limited and no power analysis has been conducted. Although many results agree with those reported in the literature, some contrasting findings might be related to the lack of experience of radiologists and no reliability analysis was conducted for all the investigated variables. Finally, the introduction of the DP sequences after the first three exams could have jeopardized the results for the assessment of LT tears.

In conclusion, the diagnosis of FAI is rather simple, but the detection of soft tissues alterations is still today challenging for the orthopaedic surgeon. An integration between clinical and radiological information is mandatory, particularly regarding MRA, which is of paramount importance for the planning of the surgical procedure. However, a certain disagreement exists between instrumental and arthroscopic findings, which should be eliminated by a proper technical accuracy of imaging exams and an improved knowledge of the pathology by all dedicated specialists.

\section{Conflict of Interest}

None.

\section{References}

1 Ganz R, Parvizi J, Beck M, Leunig M, Nötzli H, Siebenrock KA. Femoroacetabular impingement: a cause for osteoarthritis of the hip. Clin Orthop Relat Res 2003;(417):112-120

$2 \mathrm{Ng}$ VY, Arora N, Best TM, Pan X, Ellis TJ. Efficacy of surgery for femoroacetabular impingement: a systematic review. Am J Sports Med 2010;38(11):2337-2345

3 Malviya A, Stafford GH, Villar RN. Impact of arthroscopy of the hip for femoroacetabular impingement on quality of life at a mean follow-up of 3.2 years. J Bone Joint Surg Br 2012;94(04):466-470

4 Beaulé PE, Allen DJ, Clohisy JC, Schoenecker P, Leunig M. The young adult with hip impingement: deciding on the optimal intervention. J Bone Joint Surg Am 2009;91(01):210-221

5 Klaue K, Durnin CW, Ganz R. The acetabular rim syndrome. A clinical presentation of dysplasia of the hip. J Bone Joint Surg Br 1991;73(03):423-429

6 Bredella MA, Ulbrich EJ, Stoller DW, Anderson SE. Femoroacetabular impingement. Magn Reson Imaging Clin N Am 2013;21(01):45-64

7 Tannast M, Siebenrock KA, Anderson SE. Femoroacetabular impingement: radiographic diagnosis-what the radiologist should know. Am J Roentgenol 2007;188(06):1540-1552

8 Harris WH. Etiology of osteoarthritis of the hip. Clin Orthop Relat Res 1986;(213):20-33

9 Stulberg SD. Unrecognized childhood hip disease: a major cause of idiopathic osteoarthritis of the hip. In: Cordell LD, Harris WH, Ramsey PL, MacEwen GD, eds. The Hip: Proceedings of the Third Open Scientific Meeting of the Hip Society. St Louis, MO: CV Mosby; 1975:212-228

10 Byrd JW, Jones KS. Hip arthroscopy in athletes: 10-year follow-up. Am J Sports Med 2009;37(11):2140-2143

11 Philippon MJ, Briggs KK, Yen YM, Kuppersmith DA. Outcomes following hip arthroscopy for femoroacetabular impingement with associated chondrolabral dysfunction: minimum two-year follow-up. J Bone Joint Surg Br 2009;91(01):16-23 
12 Bedi A, Dolan M, Magennis E, Lipman J, Buly R, Kelly BT. Computerassisted modeling of osseous impingement and resection in femoroacetabular impingement. Arthroscopy 2012;28(02):204-210

13 Gold SL, Burge AJ, Potter HG. MRI of hip cartilage: joint morphology, structure, and composition. Clin Orthop Relat Res 2012;470 (12):3321-3331

14 Li AE, Jawetz ST, Greditzer HG IV, Burge AJ, Nawabi DH, Potter HG. MRI for the preoperative evaluation of femoroacetabular impingement. Insights Imaging 2016;7(02):187-198

15 Bulat E, Bixby SD, Siversson C, Kalish LA, Warfield SK, Kim YJ. Planar dGEMRIC maps may aid imaging assessment of cartilage damage in femoroacetabular impingement. Clin Orthop Relat Res 2016;474(02):467-478

16 Röling MA, Visser MI, Oei EHG, Pilot P, Kleinrensink G-J, Bloem RM. A quantitative non-invasive assessment of femoroacetabular impingement with CT-based dynamic simulation-cadaveric validation study. BMC Musculoskelet Disord 2015;16:50

17 Li AE, Jawetz ST, Greditzer HG IV, Burge AJ, Nawabi DH, Potter HG. MRI for the preoperative evaluation of femoroacetabular impingement. Insights Imaging 2016;7(02):187-198

18 Dunn DM. Anteversion of the neck of the femur; a method of measurement. J Bone Joint Surg Br 1952;34-B(02):181-186

19 Meyer DC, Beck M, Ellis T, Ganz R, Leunig M. Comparison of six radiographic projections to assess femoral head/neck asphericity. Clin Orthop Relat Res 2006;445(445):181-185

20 Outerbridge RE. The etiology of chondromalacia patellae. J Bone Joint Surg Br 1961;43-B:752-757

21 Weir A, Brukner P, Delahunt E, et al. Doha agreement meeting on terminology and definitions in groin pain in athletes. $\mathrm{Br} \mathrm{J}$ Sports Med 2015;49(12):768-774

22 Bedi A, Dolan M, Leunig M, Kelly BT. Static and dynamic mechanical causes of hip pain. Arthroscopy 2011;27(02):235-251

23 Leunig M, Beck M, Kalhor M, Kim YJ, Werlen S, Ganz R. Fibrocystic changes at anterosuperior femoral neck: prevalence in hips with femoroacetabular impingement. Radiology 2005;236(01):237-246
24 Smith TO, Hilton G, Toms AP, Donell ST, Hing CB. The diagnostic accuracy of acetabular labral tears using magnetic resonance imaging and magnetic resonance arthrography: a meta-analysis. Eur Radiol 2011;21(04):863-874

25 Byrd JW, Jones KS. Hip arthroscopy for labral pathology: prospective analysis with 10-year follow-up. Arthroscopy 2009;25(04):365-368

26 Ho CP, Ommen ND, Bhatia S, et al. Predictive value of 3-T magnetic resonance imaging in diagnosing grade 3 and 4 chondral lesions in the hip. Arthroscopy 2016;32(09):1808-1813

27 Mintz DN, Hooper T, Connell D, Buly R, Padgett DE, Potter HG. Magnetic resonance imaging of the hip: detection of labral and chondral abnormalities using noncontrast imaging. Arthroscopy 2005;21(04):385-393

28 González Gil AB, Llombart Blanco R, Díaz de Rada P. Validity of magnetic resonance arthrography as a diagnostic tool in femoroacetabular impingement syndrome. Rev Esp Cir Ortop Traumatol 2015;59(04):281-286

29 Sahin M, Calisir C, Omeroglu H, Inan U, Mutlu F, Kaya T. Evaluation of labral pathology and hip articular cartilage in patients with femoroacetabular impingement (FAI): comparison of multidetector CT arthrography and MR arthrography. Pol J Radiol 2014;79:374-380

30 Nepple JJ, Prather H, Trousdale RT, et al. Diagnostic imaging of femoroacetabular impingement. J Am Acad Orthop Surg 2013;21 (Suppl 1):S20-S26

31 Byrd JW, Jones KS. Traumatic rupture of the ligamentum teres as a source of hip pain. Arthroscopy 2004;20(04):385-391

32 Philippon MJ, Pennock A, Gaskill TR. Arthroscopic reconstruction of the ligamentum teres: technique and early outcomes. J Bone Joint Surg Br 2012;94(11):1494-1498

33 Martin RL, Kivlan BR, Clemente FR. A cadaveric model for ligamentum teres function: a pilot study. Knee Surg Sports Traumatol Arthrosc 2013;21(07):1689-1693

34 Botser IB, Martin DE, Stout CE, Domb BG. Tears of the ligamentum teres: prevalence in hip arthroscopy using 2 classification systems. Am J Sports Med 2011;39(Suppl):117S-125S 